\title{
National aichi biodiversity target I-an assessment in India
}

\begin{abstract}
The Aichi Biodiversity Targets are a set of twenty targets of the Convention on Biological Diversity (CBD) that were developed to prevent the loss of biological diversity in each participating country and measure the progress towards its conservation. Since India is a signatory to $\mathrm{CBD}$, the country developed a set of twelve national targets in alignment with these twenty Aichi targets aimed to conserve biodiversity. The very first target of twelve Indian targets that were set to be achieved by 2020 was about making people aware of the values of biodiversity within ten years. This article outlines the Aichi National target one and the progress made by India towards the achievement of Aichi-12.
\end{abstract}

Volume 6 Issue 2 - 2021

\author{
Kirandeep K Dhami \\ Guru Nanak Dev University, India
}

Correspondence: Dr. Kirandeep K Dhami, Guru Nanak Dev University,Amritsar (Punjab)- India,

Email kirandeepdhami@gmail.com

Received: February 18, 2021 | Published: April 28, 2021

\section{Introduction}

The protection and preservation of a variety of species on the earth ecosystem are important and necessary for several reasons: one for the maintenance of a balance in the natural ecosystem on the earth; two, to ensure the food security for the generations and three, to prevent the climate change in near future. When the loss in species diversity started to impact ecological balance and climate on earth, global initiatives were taken to conserve biological diversity. Convention on Biological Diversity was one of them that happened at the United Nations Rio Conference in 1992 with the major objective of conserving biological diversity to which 196 countries became the signatory. ${ }^{1}$ The parties to the convention tried to enforce the goals of biodiversity protection and preservation through national legislation, however, the initial failures in conservation efforts and ongoing loss of species since 1993 lead to the development of a Target Approach in 2000 and Aichi targets in 2010.,3

\section{Aichi targets}

Aichi biodiversity targets are those time-bound measurable twenty targets that have been set by all the 193 parties signatory to the convention on biological diversity (CBD) to address the biodiversity loss worldwide and promote conservation. ${ }^{4}$ These targets got developed under the target approach adopted by all the parties signatory to the convention in 2000 in two different phases, each of which was decade long. In the first phase of the target approach, a set of 21 targets was set up to significantly reduce the current rate of biodiversity loss at the regional, national and global level, to be achieved by $2010 .^{2}$ This was a commitment from all the government's signatories to the convention to biodiversity. Though substantial regional and local progress was made towards 21 targets, 2010 biodiversity targets were not met at the global scale. ${ }^{5,6}$ None of the 21 subsidiary targets to the 2010 Biodiversity Targets were completely achieved. Not a single government in the reports submitted to the CBD could claim that the 2010 biodiversity targets were completely met at the national level. Hence, 2010 targets were succeeded by another set of targets that were named as 'Aichi Biodiversity targets' to be achieved by 2020. When the state of biodiversity continued to decline despite the increase in conservation efforts, a set of twenty global objectives were set up during the $10^{\text {th }}$ meeting of parties of the Convention on Biological Diversity in 2010. This offered a more complex plan to reduce the loss of species and natural habitats and safeguard ecosystem services, while also improving planning, financing, knowledge and benefits from sustainable management of the natural world. All 193 parties to the convention on biological diversity (CBD) agreed to address the targets for the upcoming ten years period in $2010 .^{7-9}$ The targets were collectively termed as Aichi Targets, named after the location where the $10^{\text {th }}$ meet was held in Aichi Prefecture, Japan. The set of twenty targets have been organized under five strategic goals, which were set to address biodiversity loss worldwide (Table 1). These targets were required to be met by signatory countries by 2020 for which they could come up with their own plan of actions aligned with these targets as per their respective economic, geographic and technical capabilities. India developed a set of twelve targets aligned with the twenty Aichi targets and the very first national target apparently is the most important one that carries the maximum weight towards the protection and preservation of global diversity.

\section{National aichi target one in India}

In alignment with the twenty Aichi targets (Table 1), India (a signatory to $\mathrm{CBD}$ ) developed a set of twelve national targets to conserve biodiversity (Table 2). The very first target of twelve Indian targets was about making people aware of the values of biodiversity within a period of ten years. The target was set to be achieved by 2020 in a planned manner.

To increase general awareness among the public by 2020, several strategies of education were used. Firstly, since youth makes more than $50 \%$ population of the country, India planned to focus on educating the youth population in the country about biological diversity. It was important to inculcate the values of biological diversity in the target young population in the country who would set up the foundation of an eco-friendly future society in the country. Secondly, two pathways of formal and informal education were chosen to enhance awareness in the young on biological diversity and its conservation. Formal education was planned through teachings in schools, colleges and universities with curriculum changes. Informal education was planned through films, television, literature, the guidance of elders or participation in events regarding the natural environment. Thirdly, several possible indicators of increasing awareness were chosen which included the number of visits to natural history museums, zoos, botanical gardens, protected areas, parks; the number of school biodiversity education programmes; volunteer participation in relevant activities; the number of activities carried out by indigenous peoples, 
local communities and local citizen groups; and the development and use of lists of recommended actions for citizens, the private sector, and other stakeholders. Other possible indicators included were: the number of biodiversity-related news articles published in national newspapers and changes in the demand for environmentally friendly products. Fourthly, the impact of public awareness campaigns was planned to be monitored through surveys of awareness and attitudes.

Table I A summarized description of the 20 Aichi Biodiversity Targets, adapted from the Global Biodiversity Outlook (20I4) and the CBD Quick Guides for the Aichi Biodiversity Targets CBD. Unless otherwise noted, each target has 2020 as the end date ${ }^{3}$

\section{Strategic Goal A}

Address the underlying causes of biodiversity loss by mainstreaming biodiversity across government and society

Target I Make people aware of the values of biodiversity

Target 2 Integrated biodiversity values in development + poverty reduction plan

Target 3 Subsidies that are harmful to biodiversity= and eliminate them, phase them out or reform them

Target 4 Sustainable production and consumption.

\section{Strategic Goal B}

Reduce the direct pressures on biodiversity and promote sustainable use

Target 5 Reduce the rate of natural habitat loss + forest loss by at least $50 \%$

Target $6 \quad$ Reduce overfishing

Target 7 Agriculture, aquaculture, and forestry in a sustainable manner

Target 8 Reduce pollution and excessive use of fertilizer

Target 9 Prevent invasive alien species (non-native)

Target 10 Minimize the choral reflow destruction, ocean acidification

\section{Strategic Goal C}

To improve the status of biodiversity by safeguarding ecosystems, species and genetic diversity

Target II Conserve terrestrial and inland water, coastal - marine areas

Target 12 Prevent the extinction of threatened species

Target 13 Maintain genetic diversity of agro-plants, domesticated animals and minimizing genetic erosion

\section{Strategic Goal C}

To improve the status of biodiversity by safeguarding ecosystems, species and genetic diversity

Target II Conserve terrestrial and inland water, coastal - marine areas

Target 12 Prevent the extinction of threatened species

Target 13 Maintain genetic diversity of agro-plants, domesticated animals and minimizing genetic erosion

\section{Strategic Goal D}

Enhance the benefits to all from biodiversity and ecosystem services

Target 14 Safeguard ecosystems for women, tribals, and the poor.

Target $15 \quad$ Combat desertification and restore the degraded ecosystem

Target 16 Operationalize the Nagoya protocol on genetic resources, via national legislations

\section{Strategic Goal E}

Enhance implementation through participatory planning, knowledge management and capacity building

Target 17 National biodiversity strategy and action plans - update for participation

Target $18 \quad$ Integrate the knowledge of tribal communities

Target 19 Scientific and technological knowledge sharing application

Target $20 \quad$ Financial resources mobilization 
Table 2 A set of twelve National biodiversity targets in India developed in alignment with twenty aichi targets

\section{National Biodiversity Target I}

By 2020 , a significant proportion of the country's population, especially the youth, is aware of the values of biodiversity and the steps they can take to conserve and use it sustainably

\section{National Biodiversity Target 2}

By 2020 , values of biodiversity are integrated into National and State planning processes, development programmes and poverty alleviation strategies.

\section{National Biodiversity Target 3}

Strategies for reducing the rate of degradation, fragmentation and loss of all natural habitats are finalized and actions put in place by 2020 for environmental amelioration and human well-being

\section{National Biodiversity Target 4}

By 2020, invasive alien species and pathways are identified and strategies to manage them developed so that populations of prioritized invasive alien species are managed.

\section{National Biodiversity Target 5}

By 2020, measures are adopted for sustainable management of agriculture, forestry, and fisheries.

\section{National Biodiversity Target 6}

Ecologically representative areas on land and in inland waters, as well as coastal and marine zones, especially those of particular importance for species, biodiversity and ecosystem services, are conserved effectively and equitably, based on PA designation and management and other area-based conservation measures and are integrated into the wider landscapes and seascapes, covering over $20 \%$ of the geographic area of the country, by 2020 .

\section{National Biodiversity Target 7}

By 2020, genetic diversity of cultivated plants, farm livestock and their wild relatives, including other socioeconomically as well as culturally valuable species, is maintained, and strategies have been developed and implemented for minimizing genetic erosion and safeguarding their genetic diversity

\section{National Biodiversity Target 8}

By 2020 , ecosystem services, especially those relating to water, human health, livelihoods and wellbeing, are enumerated and measures to safeguard them are identified, taking into account the needs of women and local communities, particularly the poor and vulnerable sections.

\section{National Biodiversity Target 9}

By 2015, Access to Genetic Resources and the Fair and Equitable Sharing of Benefits Arising from their Utilization as per the Nagoya Protocol are operational, consistent with national legislation.

\section{National Biodiversity Target 10}

By 2020, an effective, participatory and updated national biodiversity action plan is made operational at different levels of governance.

\section{National Biodiversity Target I I}

By 2020, national initiatives using communities' traditional knowledge relating to biodiversity are strengthened, to protect this knowledge following national legislations and international obligations

\section{National Biodiversity Target 12}

By 2020, opportunities to increase the availability of financial, human and technical resources to facilitate effective implementation of the Strategic Plan for Biodiversity 20I I-2020 and the national targets are identified and the Strategy for Resource Mobilization is adopted.

In the 6th National biodiversity target report submitted on 29th December 2018, India claimed that a significant proportion of the country's population, especially the youth, is aware of the values of biodiversity and the steps they can take to conserve and use it sustainably by 2020 .

Despite the claims, it becomes very important to do a reality check at ground level. Are these claims based upon any survey on biological diversity and its values amongst the general public? If yes, then what percentage of the youth population is aware of the biodiversity, its values and conservation? Assuming people already aware of the values of biological diversity, then we must expect some personal initiative at the local or regional level to protect biological diversity. A good indicator for which could be a love for nature in the society in general, enhanced plantations in the homes, reforestation or afforestation drives. Are we seeing that in the country?? A biological diversity aware society must be able to create a beautiful diverse natural environment most sustainably in the urbanized settings. A biodiversity aware individual must be naturally willing to take some initiative in the best possible way to contribute towards the protection of biodiversity in general. Do people around in the society doing some effort to protect the trees around, plant more trees in general? It is known that the Indian universities colleges and schools have 
been teaching biodiversity and environmental sciences as part of the curriculum, organizing seminars, webinars and small events to generate general awareness among youngsters of the values of biodiversity. Despite the formal education, what percentage of young adopts a lifestyle that expresses a concern for biological diversity is still questionable. Have we observed a reduction in the list of critically endangered, endangered or threatened species by the end of decade long effort?? Or if it is too early to expect such drastic results, do we observe initiatives at local and regional scale towards conservation of species??

\section{Conclusion}

There is no doubt various efforts have been put in place to enlighten the youth on the values of biological diversity and its conservation. Despite various initiatives of formal and informal education to achieve Aichi biodiversity target one, apparently scenario hasn't changed much in this past few years at ground level in the country. Prolonged education at school, college and university level is a must to get the young minds attracted and attached to biological diversity, its values and conservation. Simply including the topic in the curriculum for the sake of distributing diplomas and degrees cannot serve the purpose. Every individual must begin to feel the personal responsibility towards the conservation of a variety of species and there is no other way but education regarding biodiversity, its values and conservation can serve to achieve the goals.

\section{Acknowledgments}

None.

\section{Funding}

None.

\section{Conflicts of interest}

The authors declare that there is no conflict of interest.

\section{References}

1. United Nations. United Nations convention on biological diversity. UNCED, Rio de Janeiro; 1993.

2. CBD. Handbook of the convention on biological diversity. London: Earthscan; 2003.

3. CBD. COP decision $\mathrm{X} / 2$. Strategic plan for biodiversity 2011-2020. 2010.

4. Convention on Biological Diversity. Aichi biodiversity targets. 2018.

5. Butchart SHM, Walpole M, Collen B, et al. Global biodiversity: indicators of recent declines. Science. 2010;328:1164-1168.

6. CBD. Global biodiversity outlook 3. Convention on biological diversity, Montreal; 2010.

7. SCBD. Decision adopted by the conference of the parties to the convention on biological diversity at its tenth meeting. X/2. The Strategic Plan for Biodiversity 2011-2020 and the Aichi Biodiversity Targets. 2010.

8. SCBD. Progress towards the Aichi biodiversity targets: an assessment of biodiversity trends, policy scenarios and key actions: Global biodiversity outlook 4 (GBO-4) technical report. Montreal, Quebec, Canada: Secretariat of the Convention on Biological Diversity (CBD); 2014.

9. SCBD. Convention on biological diversity. List of Parties. Convention on Biological Diversity; 2016. 